\title{
Steroids and Flavonoids of Porcelia macrocarpa
}

\author{
Mariana H. Chaves ${ }^{a}$, Nidia F. Roque ${ }^{*, b}$ and Mariane C. Costa Ayres \\ ${ }^{a}$ Departamento de Química, Universidade Federal do Piauí, Campus Ininga, 64049-550 Teresina - PI, Brazil \\ ${ }^{b}$ Instituto de Química, Universidade de São Paulo, CP 26077, 05513-970 São Paulo - SP, Brazil and Instituto de \\ Química, Universidade Federal da Bahia, 40170-290 Salvador - BA, Brazil
}

\begin{abstract}
Três misturas de esteróides $(\mathbf{1} \mathbf{a}+\mathbf{1 b}, \mathbf{2} \mathbf{a}+\mathbf{2} \mathbf{b}$ e $\mathbf{3 a}+\mathbf{3 b})$ e dois flavonóides glicosilados (4 e 5) foram isolados do extrato etanólico dos galhos da Porcelia macrocarpa (Warm.) R. E. Fries (Annonaceae). Os esteróides Estigmasta-4,25-dien-3-ona (2a) e (22E)-Estigmasta-4,22,25-trien-3ona (2b) são substâncias novas. As estruturas foram determinadas com base na análise de dados espectrais de RMN e de massas e por comparação com dados de substâncias da literatura usadas como modelos.
\end{abstract}

Three mixtures of steroids $(\mathbf{1} \mathbf{a}+\mathbf{1 b}, \mathbf{2} \mathbf{a}+\mathbf{2} \mathbf{b}$ and $\mathbf{3 a}+\mathbf{3 b})$ and two flavonoid glycosides $(\mathbf{4}$ and $\mathbf{5})$ were isolated from the ethanol extract of branches of Porcelia macrocarpa (Warm.) R. E. Fries (Annonaceae). The steroids Stigmasta-4,25-dien-3-one (2a) and (22E)-Stigmasta-4,22,25-trien-3one (2b) are news. The structures were elucidated by NMR and MS data and comparison with literature data of model compounds.

Keywords: Porcelia macrocarpa, Annonaceae, steroids, flavonoids

\section{Introduction}

Porcelia macrocarpa is a botanical species from Annonaceae family and the only one of the genus occurring in Brazil. ${ }^{1}$ This species has a very diversified chemical composition, revealed by isolation of acetogenins, lignanamides, hydroxycinnamoyltyramines, sesquiterpenes and alkaloids, including azapolycyclics, from different parts, previously investigated, of the same specimen. ${ }^{2-6}$

This paper describes the isolation and identification of three steroid mixtures and two flavonoid glycosides from the ethanol extract of the branches of Porcelia macrocarpa.

\section{Results and Discussion}

The ether soluble part from the ethanol extract of the branches of Porcelia macrocarpa was submitted to a partition between hexane and aqueous methanol. Chromatographic separation of the hexane phase afforded two steroid mixtures (M1 and M2) and the hydroalcoholic phase gave, after the same procedure, one mixture of steroid

* e-mail: nifroque@ufba.br glycosides (M3). An insoluble material precipitated in the interface between diethyl ether and water, during the partition from the ethanol extract, afforded two flavonoid glycosides $\mathbf{4}$ and $\mathbf{5}$.

A GCMS analysis of the M1 mixture showed two compounds $\mathbf{1 a}$ and $\mathbf{1 b}$ in a 5:2 relationship, where the major compound presents a molecular peak $[\mathrm{M}]^{+}$at $\mathrm{m} / \mathrm{z}$ 412 and the minor one at $\mathrm{m} / \mathrm{z} 410$. The ${ }^{1} \mathrm{H}$ NMR spectrum (Table 1) of the mixture M1 showed signals at $\delta 3.51(\mathrm{~m})$, $5.34(\mathrm{~m})$ and between $\delta 0.6$ and 1.6 attributed to $\mathrm{H}-3, \mathrm{H}-6$ and methyl hydrogens, respectively, from a $\Delta^{5}-3 \beta$-hydroxy sterol with an allylic methyl group. ${ }^{7}$ Signals at $\delta$ 5.23-5.17 and 4.72-4.62 suggested additional double bonds in the steroidal nucleus. The ${ }^{1} \mathrm{H}$ and ${ }^{13} \mathrm{CNMR}$ data agree with the structure of $\Delta^{5}$ sterols $\left[\delta_{\mathrm{C}} 71.8\right.$ (oxygenated $\mathrm{CH}-3$ ), 140.7 (C-5) and 121.7 (CH-6)] containing additionally one (1a, $[\mathbf{M}]^{+}$at $m / z$ 412) and two double bonds $\left(\mathbf{1 b},[\mathbf{M}]^{+}\right.$at $m / z$ 410) located at the side chain. The side chain of both steroids sustain an ethyl group at C-24, as in sitosterol. The presence in the mixture of two methylidene groups $\left(\mathrm{C}=\mathrm{CH}_{2}\right)$ was deduced by ${ }^{13} \mathrm{C}$ signals corresponding to $\mathrm{sp}^{2}$ non-hydrogenated and methylene carbon atoms $\left[\delta_{\mathrm{C}} 147.5\right.$ and 111.4 (1a); 148.6 and 109.5 (1b)]. Thus, the second double bond of 1 a was placed at $\mathrm{C}-25$ to justify the ${ }^{13} \mathrm{C}$ signals and the allylic methyl group in the ${ }^{1} \mathrm{H}$ NMR (Table 
Table 1. ${ }^{1} \mathrm{H}$ NMR data for $\mathbf{1 a}, \mathbf{1 b}, \mathbf{2 a}, \mathbf{2 b}, \mathbf{3 a}$ and $\mathbf{3 b}\left(200 \mathrm{MHz}, \mathrm{CDCl}_{3}\right)$

\begin{tabular}{|c|c|c|c|}
\hline $\mathrm{C}$ & $1 a+1 b$ & $2 a+2 b$ & $3 a+3 b^{a}$ \\
\hline 3 & 3.51 & - & 3.91 \\
\hline 4 & - & 5.72 & - \\
\hline 6 & 5.34 & - & 5.33 \\
\hline $22 / 23$ & $5.17-5.23$ & $5.19-5.23$ & $5.28-5.31$ \\
\hline 27 & 4.62-4.72 (0nly 1b) & $4.65-4.70($ Only $\mathbf{2 b})$ & 4.53-4.59 (Only 3b) \\
\hline Me-26 & 1.56 or 1.46 & 1.65 or 1.57 & 1.61 or 1.72 \\
\hline glucopyranosyl & - & - & $4.26-5.06$ \\
\hline
\end{tabular}

${ }^{a}$ Compounds $\mathbf{3 a}+\mathbf{3 b}$ were measured in $\mathrm{C}_{5} \mathrm{D}_{5} \mathrm{~N}$.

1 and 2). The peak at $m / z 84(19 \%)$ attributed to fragment 1a-F originated by a McLafferty rearrangement (Table 3 and Figure 1) is in accordance with this suggestion. The compound 1a has been isolated before from the marine green alga Codium iyengarii. ${ }^{8}$ The low relative intensity of the peak at $\mathrm{m} / \mathrm{z} 84(3 \%)$ observed in the mass spectrum of $\mathbf{1 b}$ is justified by the presence of another peak at $\mathrm{m} / \mathrm{z}$ $138(43 \%)$ attributed to the fragment $\mathbf{1 b}$-D formed also by

Table 2. ${ }^{13} \mathrm{C}$ NMR spectral data of steroids $\mathbf{1 a}, \mathbf{1 b}, \mathbf{2 a}, \mathbf{2} \mathbf{b}, \mathbf{3 a}$ and $\mathbf{3 b}$ $\left(50.3 \mathrm{MHz}, \mathrm{CDCl}_{3}\right)$

\begin{tabular}{|c|c|c|c|c|c|c|}
\hline $\mathrm{C}$ & $1 \mathrm{a}$ & $1 \mathrm{~b}$ & $2 a$ & $2 b$ & $3 \mathbf{a}^{\mathrm{d}}$ & $\mathbf{3} \mathbf{b}^{\mathrm{d}}$ \\
\hline 1 & 37.2 & 37.2 & 35.7 & 35.7 & 38.0 & 38.0 \\
\hline 2 & 31.6 & 31.6 & 34.0 & 34.0 & 30.7 & 30.7 \\
\hline 3 & 71.8 & 71.8 & 199.6 & 199.6 & 79.1 & 79.1 \\
\hline 4 & 42.3 & 42.3 & 123.8 & 123.8 & 40.4 & 40.3 \\
\hline 5 & 140.7 & 140.7 & 171.7 & 171.7 & 141.4 & 141.4 \\
\hline 6 & 121.7 & 121.7 & 32.9 & 32.9 & 122.4 & 122.4 \\
\hline 7 & 31.9 & 31.9 & 32.0 & 32.0 & $32.6^{\mathrm{a}}$ & 32.6 \\
\hline 8 & 31.9 & 31.9 & 35.6 & 35.5 & 32.5 & 32.5 \\
\hline 9 & 50.1 & 50.1 & 53.8 & 53.8 & 50.8 & 50.8 \\
\hline 10 & 36.5 & 36.5 & 38.6 & 38.6 & 37.4 & 37.4 \\
\hline 11 & 21.1 & 21.1 & 21.0 & 21.0 & 21.8 & 21.8 \\
\hline 12 & 39.7 & 39.6 & 39.6 & 39.5 & 39.8 & 39.8 \\
\hline 13 & 42.3 & 42.3 & 42.3 & 42.3 & 43.0 & 42.8 \\
\hline 14 & $56.7^{\mathrm{a}}$ & $56.8^{\mathrm{a}}$ & $56.0^{\mathrm{b}}$ & $56.0^{\mathrm{a}}$ & $57.3^{\mathrm{b}}$ & $57.3^{\mathrm{a}}$ \\
\hline 15 & 24.3 & 24.3 & 24.2 & 24.2 & 25.0 & 25.0 \\
\hline 16 & 28.1 & 28.7 & 28.1 & 28.6 & $28.9^{c}$ & 29.5 \\
\hline 17 & $56.0^{\mathrm{a}}$ & $55.8^{\mathrm{a}}$ & $55.9^{\mathrm{b}}$ & $55.8^{\mathrm{a}}$ & $56.7^{b}$ & $56.5^{\mathrm{a}}$ \\
\hline 18 & 11.8 & $12.1^{\mathrm{b}}$ & 12.0 & $11.9^{\mathrm{b}}$ & 12.5 & $12.6^{\mathrm{b}}$ \\
\hline 19 & 19.4 & 19.4 & 17.4 & 17.4 & 19.9 & 19.9 \\
\hline 20 & 35.5 & 40.2 & 35.6 & 40.6 & 35.7 & 40.9 \\
\hline 21 & 18.6 & $20.8^{c}$ & 18.6 & $20.7^{c}$ & 19.4 & $21.5^{\mathrm{c}}$ \\
\hline 22 & 33.6 & 137.2 & 33.6 & 137.0 & $34.5^{\mathrm{a}}$ & 138.1 \\
\hline 23 & 29.4 & 130.0 & 29.4 & 130.2 & $30.2^{\mathrm{c}}$ & 130.8 \\
\hline 24 & 49.5 & 52.0 & 49.5 & 52.0 & 50.2 & 52.8 \\
\hline 25 & 147.5 & 148.6 & 147.5 & 148.5 & 148.2 & 149.1 \\
\hline 26 & 177.0 & $20.2^{\mathrm{c}}$ & 17.8 & $20.2^{\mathrm{c}}$ & 18.4 & $20.8^{\mathrm{c}}$ \\
\hline 27 & 111.4 & 109.5 & 111.4 & 109.6 & 112.4 & 110.6 \\
\hline 28 & 26.5 & 25.7 & 26.7 & 26.7 & 27.2 & 26.5 \\
\hline 29 & 12.1 & $12.1^{\mathrm{b}}$ & 12.1 & $12.1^{\mathrm{b}}$ & 12.8 & $12.9^{\mathrm{b}}$ \\
\hline
\end{tabular}

${ }^{d}$ Compounds 3a $+3 \mathbf{3 b}$ were measured in $\mathrm{C}_{5} \mathrm{D}_{5} \mathrm{~N}$. Assignments with the same symbol $(\mathbf{a , b , c})$ in the column are interchangeable. Signals for carbons of the glucosyl moiety in compounds $\mathbf{3 a}$ and $\mathbf{3 b}$ occurred at $\delta 103.0\left(\mathrm{C}^{\prime} \mathbf{1}^{\prime}\right), 75.8\left(\mathrm{C}^{\prime} 2^{\prime}\right), 78.6$ (C-3'), 72.2 (C-4'), 78.9 (C-5'), 63.3 (C-6'). a McLafferty rearrangement involving the additional double bond localized between the carbon atoms C-22 and C-23 (Table 3 and Figure 1). This third double bond is present only in $\mathbf{1 b}$, as indicated by the ${ }^{1} \mathrm{H}$ NMR multiplet integration at $\delta$ 5.23-5.17 and by the molecular ion. The $\mathrm{CH}$ signals at $\delta 137.2$ and 130.0 observed in the ${ }^{13} \mathrm{C}$ NMR spectrum (Table 2) are in accordance with the proposed structure. Compound $\mathbf{1 b}$ is also described in the literature.

The GC-MS of M2 showed two compounds, in the same proportion of M1, with molecular peaks at $m / z 410$ and 408 (Table 3). The ${ }^{1} \mathrm{H}$ NMR spectrum (Table 1) was very similar with that of M1, but presented a signal at $\delta$ 5.72 instead of the signals at $\delta 3.51$ and 5.34, suggesting a $\Delta^{4}$ conjugated double bond as in sitostenone. ${ }^{9}$ The ${ }^{13} \mathrm{C}$ NMR spectra (Table 2) showed signals that confirmed this suggestion, when compared with literature data of model compounds. ${ }^{10}$ The MS fragmentation followed the same pattern as M1 (Figure1 and Table 3). Hydrogenation of M2 mixture, at room pressure, gave the steroid sitostenone, as proved by GCMS and ${ }^{1} \mathrm{H}$ NMR spectra. ${ }^{9}$ M2 is then composed by a mixture of $\mathbf{2} \mathbf{a}$ and $\mathbf{2} \mathbf{b}$ which are described here for the first time.

The ${ }^{1} \mathrm{H}$ NMR spectrum (Table 1 ) of $\mathbf{M 3}$ differs from that of M1 only in the carbinolic hydrogen region. It showed signals between, $\delta 4.05$ and 5.07, from a sugar unit. The H-3 multiplet is deshielded by $0.4 \mathrm{ppm}$ suggesting that the mixture is composed by, glycopyranosyl steroids, with $\beta$ configuration on the anomeric carbon, evidenced by the doublet at $\delta 5.02$ (7.6 Hz). ${ }^{11}$ The ${ }^{13} \mathrm{C}$ NMR (Table 2) data suggested that the

Table 3. Mass spectrometric fragments of the side-chain of steroids $\mathbf{1 a}, \mathbf{1 b}, \mathbf{2} \mathbf{a}$ and $\mathbf{2 b} \mathrm{m} / \mathrm{z}$ (rel. int.)

\begin{tabular}{lcccc}
\hline Fragments & $\mathbf{1 a}$ & $\mathbf{1 b}$ & $\mathbf{2 a}$ & $\mathbf{2 b}$ \\
\hline$[\mathrm{M}]^{+}$ & $412(20)$ & $410(5)$ & $410(18)$ & $408(8)$ \\
$\mathrm{A}$ & $273(4)$ & $273(9)$ & $271(10)$ & $271(36)$ \\
$\mathrm{B}$ & $383(1)$ & $381(5)$ & $381(1)$ & $379(14)$ \\
$\mathrm{C}$ & $272(9)$ & $272(23)$ & $270(15)$ & $270(36)$ \\
$\mathrm{D}$ & $138(5)$ & $138(43)$ & $138(5)$ & $138(25)$ \\
$\mathrm{E}$ & $271(21)$ & $271(52)$ & $269(30)$ & $269(100)$ \\
$\mathrm{F}$ & $84(19)$ & $84(3)$ & $84(52)$ & $84(6)$ \\
\hline
\end{tabular}




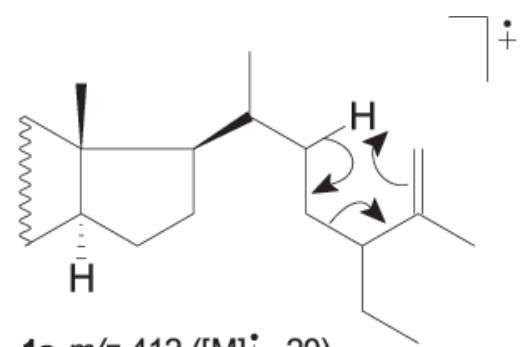

1a $\mathrm{m} / \mathrm{z} 412([\mathrm{M}] \dot{\mathrm{i}}, 20)$

2a $\mathrm{m} / \mathrm{z} 410([\mathrm{M}]+, 18)$
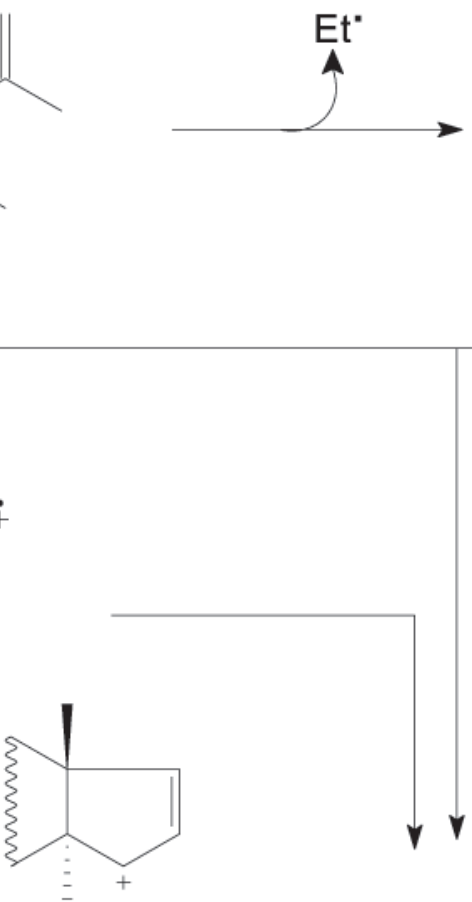

1a-E m/z 271 (21)

1b-E $\mathrm{m} / \mathrm{z} 271$ (52)

2a-E $m / z 269$ (30)

2b-E m/z 269 (100)

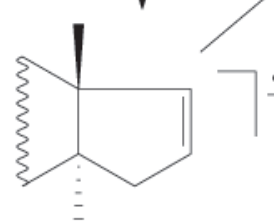

1a-C $\mathrm{m} / \mathrm{z} 272$ (9)

1b-C $\mathrm{m} / \mathrm{z} 272$ (23)

2a-C $m / z 270$ (15)

2b-C $\mathrm{m} / \mathrm{z} 270$ (36)

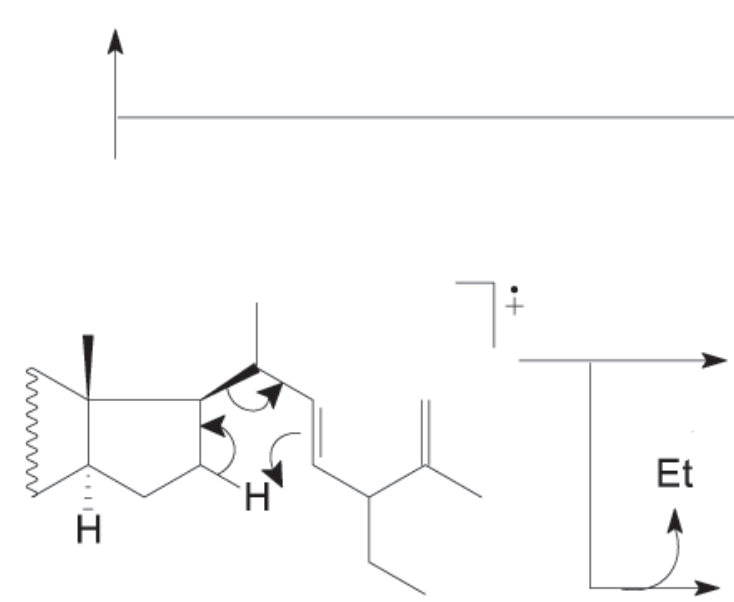

1a $\mathrm{m} / \mathrm{z} 410([\mathrm{M}]+, 5)$

2b $\mathrm{m} / \mathrm{z} 408$ ([M]+, 8)

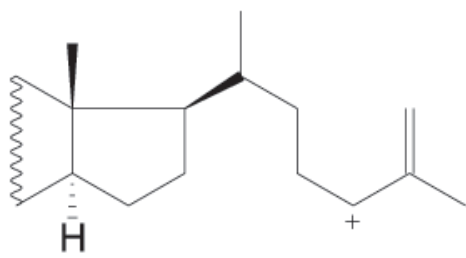

1a-B $m / z 383$ (1)

2a-B $m / z 381$ (1)

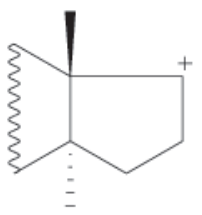

1a-A $\mathrm{m} / \mathrm{z} 273$ (4) 1b-A $\mathrm{m} / \mathrm{z} 273$ (9) 2a-A $m / z 271$ (10) 2b-A $m / z 271$ (36)

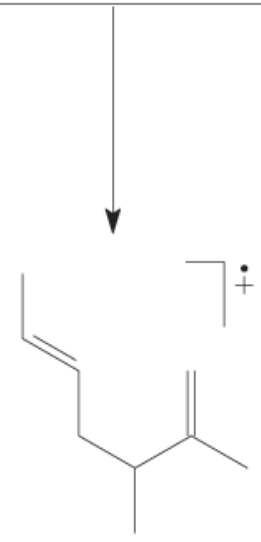

1a-D m/z 138 (5)

1b-D $\mathrm{m} / \mathrm{z} 138$ (43) 2a-D $m / z 138$ (5)

2b-D m/z 138 (25)

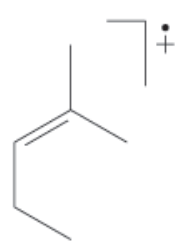

1a-F $\mathrm{m} / \mathrm{z} 84$ (19)

1b-F $\mathrm{m} / \mathrm{z} 84$ (3)

2a-F $m / z \quad 84$ (52)

2b-F $\mathrm{m} / \mathrm{z} \quad 84$ (6)

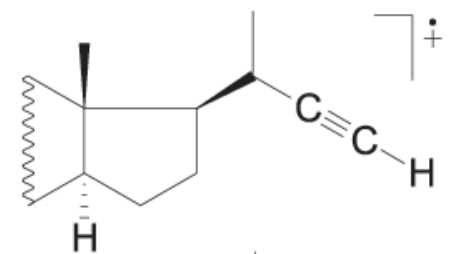

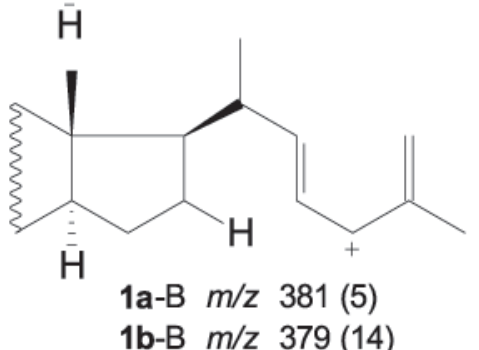

Figure 1. Proposed fragmentation patterns for side chain of steroids $\mathbf{1 a}, \mathbf{1 b}, \mathbf{2 a}$ and $\mathbf{2 b}$. 
compounds are steroid glucosides. ${ }^{11,12}$ All the other signals are compatible with the structure of $\mathbf{3 a}$ and $\mathbf{3 b}$. The steroid 3a has been isolated from Clerodendron colebrookianum (Verbenaceae). ${ }^{11}$

The ${ }^{1} \mathrm{H}$ NMR spectrum of 4 (Table 4 ) showed five signals in the aromatic region with the pattern of the flavonoid quercetin. ${ }^{13}$ Besides of those a singlet at $\delta 3.84(6 \mathrm{H})$ and signals between $\delta 3.05$ and $\delta 5.35$ were assigned to methoxyl groups and sugar hydrogens respectively. A doublet at $\delta$ 0.95 suggested that rhamnose should be present in the molecule and the singlet at $\delta 12.5$ indicated the presence of one hydroxyl at C-5 of the aglycone. The ${ }^{13} \mathrm{C}$ NMR spectrum (Table 5) showed 29 signals indicating that two sugar units and two methoxyl groups are present in the flavonoid. The chemical shifts of the sugar moiety are consistent with those of rutinosyl (rhamnopyranosyl-( $1 \rightarrow 6)$ glucopyranosyl). Comparison between the ${ }^{13} \mathrm{CNMR}$ data of $\mathbf{4}$ with those of 7,4'-dimethoxyquercetin $(\mathbf{6})^{13,14}$ showed that C-3 is shielded and C-2, C-4 and C-10 are deshielded in agreement with the glycosylation at $\mathrm{C}-3$ of $\mathbf{4}^{14-16}$

The ${ }^{1} \mathrm{H}$ NMR spectrum of 5 (Table 4) had the same pattern as that of $\mathbf{4}$ but the signal of C-5 OH was absent. The ${ }^{13} \mathrm{C}$ NMR spectrum showed 33 signals indicating the presence of 3 sugar units in the dimethoxyflavonoid, one of them should be linked to C-5. Signals of rutinosyl and glucosyl groups were present. Hydrolysis of $\mathbf{5}$ led to the isolation of 7,4'-dimethoxyquercetin (6). ${ }^{14}$ To determine which group, glicosyl or rutinosyl is bounded to C-5, a COLOC ${ }^{1} \mathrm{H}-{ }^{13} \mathrm{C}$ was obtained and a long range correlation between $\delta 4.84$, assigned to the anomeric hydrogen of glucose and $\delta 158.6$, assigned to $\mathrm{C}-5$ of the flavonoid was observed. To confirm the structure of $\mathbf{5}$ as quercetin-5-Oglucoside-3-O-rutinoside-7,4'-dimethyl ether a comparison between the ${ }^{13} \mathrm{C}$ NMR data of $\mathbf{4}$ and $\mathbf{5}$ and those of 5glucopyranosyl luteolin and luteolin ${ }^{17}$ was made. The difference found in the chemical shifts of rings $\mathrm{A}$ and $\mathrm{C}$ of

Table 4. ${ }^{1} \mathrm{H}$ NMR data of flavonoids 4, 5 and $6(200 \mathrm{MHz}, \delta$, multiplicity, $J / \mathrm{Hz}$ DMSO-d ${ }_{6}$ )

\begin{tabular}{llll}
\hline $\mathrm{H}$ & $\mathbf{4}$ & $\mathbf{5}$ & $\mathbf{6}$ \\
\hline 6 & $6.35(\mathrm{~s})$ & $6.83(\mathrm{~d}, 2.2)$ & $6.33(\mathrm{~d}, 1.6)$ \\
8 & $6.67(\mathrm{~s})$ & $6.91(\mathrm{~d}, 2.2)$ & $6.70(\mathrm{~d}, 1.4)$ \\
$2^{\prime}$ & $7.52(\mathrm{~d}, 1.9)$ & $7.53(\mathrm{~d}, 2.0)$ & $7.70(\mathrm{~s})$ \\
5 & $7.02(\mathrm{~d}, 8.7)$ & $7.01(\mathrm{~d} 8.8)$ & $7,07(\mathrm{~d}, 8.3)$ \\
$6^{\prime}$ & $7.70(\mathrm{~d}, 8.7)$ & $7.73(\mathrm{~d}, 8.8 ; 2.0)$ & $7.68(\mathrm{dd}, 8.4)$ \\
$1^{\mathrm{G}}$ & $5.30(\mathrm{~d}, 7.0)$ & $5.24(\mathrm{~d}, 7.1)$ & - \\
$1^{\mathrm{R}}$ & $4.40(\mathrm{sl})$ & $4.39(\mathrm{sl})$ & - \\
$6^{\mathrm{R}}$ & $0.95(\mathrm{~d}, 6.0)$ & $0.96(\mathrm{~d}, 5.7)$ & - \\
$1^{\mathrm{G}}$ & - & $4.84(\mathrm{~d}, 7.2)$ & - \\
$\mathrm{OMe}-4$ & $3.84(\mathrm{~s})$ & $3.85(\mathrm{~s})$ & $3.84(\mathrm{~s})$ \\
$\mathrm{OMe}-7$ & $3.84(\mathrm{~s})$ & $3.87(\mathrm{~s})$ & $3.85(\mathrm{~s})$ \\
$5-\mathrm{OH}$ & $12.5(\mathrm{~s})$ & - & $12.4(\mathrm{~s})$ \\
\hline
\end{tabular}

$\mathrm{G}=$ Glucosyl; $\mathrm{R}=$ Rhamnopyranosyl those flavonoids confirmed the proposed structure, as showed in Table 6.

Table 5. ${ }^{13} \mathrm{C}$ NMR data of flavonoids 4,5 and 6 (200 and $50.3 \mathrm{MHz}$, $\delta, \mathrm{DMSO}_{6}$ )

\begin{tabular}{|c|c|c|c|c|}
\hline $\mathrm{C}$ & 4 & 5 & ${ }^{1} \mathrm{H} \mathrm{x}{ }^{13} \mathrm{C}-\mathrm{COLOC}(\mathbf{5})$ & 6 \\
\hline 2 & $157.1^{\mathrm{a}}$ & 155.0 & 7.53 (H-2'), 7.73 (H-6') & 147.0 \\
\hline 3 & 134.1 & 136.2 & - & 136.7 \\
\hline 4 & 177.8 & 173.5 & - & 176.3 \\
\hline 5 & 161.2 & 158.6 & $6.83(\mathrm{H}-6), 4.84\left(\mathrm{H}-1^{\mathrm{G}^{\prime}}\right)$ & 160.6 \\
\hline 6 & 98.3 & 102.7 & $6.91(\mathrm{H}-8)$ & 97.8 \\
\hline 7 & 165.5 & 164.1 & $\begin{array}{c}6.83(\mathrm{H}-6) \\
6.91(\mathrm{H}-8), 3.87(\mathrm{OMe}-7)\end{array}$ & 165.2 \\
\hline 8 & 92.6 & 96.0 & $6.83(\mathrm{H}-6)$ & 92.2 \\
\hline 9 & $156.7^{\mathrm{a}}$ & 158.0 & $6.91(\mathrm{H}-8)$ & 156.4 \\
\hline 10 & 105.3 & 109.2 & $6.83(\mathrm{H}-6), 6.91(\mathrm{H}-8)$ & 104.3 \\
\hline 1 ' & 121.9 & 121.8 & $7.53\left(\mathrm{H}-2^{\prime}\right)$ & 123.6 \\
\hline 2 , & 116.1 & 116.1 & $7.73\left(\mathrm{H}-6^{\prime}\right)$ & 115.0 \\
\hline 3 , & 146.1 & 146.1 & 7.53 (H-2'), $7.01\left(\mathrm{H}-5^{\prime}\right)$ & 146.4 \\
\hline $4^{\prime}$ & 150.5 & 150.3 & $\begin{array}{c}7.53\left(\mathrm{H}-2^{\prime}\right), 7.73\left(\mathrm{H}^{\prime} 6^{\prime}\right) \\
3.85\left(\mathrm{OMe}-4^{\prime}\right)\end{array}$ & 149.7 \\
\hline $5^{\prime}$ & 111.6 & 111.4 & - & 112.0 \\
\hline $6^{\prime}$ & 122.7 & 122.7 & $7.01\left(\mathrm{H}-5^{\prime}\right)$ & 120.1 \\
\hline $1^{\mathrm{G}}$ & 101.5 & 101.6 & - & - \\
\hline $2^{\mathrm{G}}$ & 74.3 & 74.4 & - & - \\
\hline $3^{\mathrm{G}}$ & 76.7 & 76.0 & - & - \\
\hline $4^{\mathrm{G}}$ & 70.2 & 70.1 & - & - \\
\hline $5^{\mathrm{G}}$ & 76.1 & 76.0 & - & - \\
\hline $6^{\mathrm{G}}$ & 67.2 & 67.1 & - & - \\
\hline $1^{\mathrm{R}}$ & 101.1 & 101.1 & - & \\
\hline $2^{R}$ & 70.7 & 70.7 & $4.39\left(\mathrm{H}-1^{\mathrm{R}}\right)$ & - \\
\hline $3^{R}$ & 70.9 & 70.9 & - & - \\
\hline $4^{R}$ & 72.1 & 72.2 & - & - \\
\hline $5^{\mathrm{R}}$ & 68.6 & 68.6 & $4.39\left(\mathrm{H}-1^{\mathrm{R}}\right)$ & - \\
\hline $6^{\mathrm{R}}$ & 18.0 & 18.1 & - & - \\
\hline $1^{\mathrm{G}^{\prime}}$ & - & 103.9 & - & - \\
\hline $2^{\mathrm{G}^{\prime}}$ & - & 73.9 & - & - \\
\hline $3^{G^{\prime}}$ & - & 76.8 & - & - \\
\hline $4^{G^{\prime}}$ & - & 70.1 & - & - \\
\hline $5^{G^{\prime}}$ & - & 77.9 & - & - \\
\hline $6^{\mathrm{G}^{\prime}}$ & - & 61.2 & - & - \\
\hline $\mathrm{OMe}-4$ ' & 55.9 & 56.0 & - & $55.9^{\mathrm{b}}$ \\
\hline OMe-7 & 56.4 & 56.5 & - & $56.3^{\mathrm{b}}$ \\
\hline
\end{tabular}

Assignments with the same symbol in the column are interchangeable $\mathrm{G}=$ glucosyl; R=Rhamnopyranosyl.

Table 6. Differences found in the carbon chemical shifts of rings A and $\mathrm{C}$ between $\mathbf{5}$ and $\mathbf{4}$ and those between 5-glucopyranosyl luteolin and luteolin

\begin{tabular}{lcc}
\hline $\mathrm{C}$ & $\Delta \delta$ 5-glycopyranosyl luteolin-luteolin & $\Delta \delta \mathbf{5 - 4}$ \\
\hline 2 & -2.8 & -2.1 \\
3 & +2.2 & +2.1 \\
4 & -6.0 & -4.3 \\
5 & -2.7 & -2.6 \\
6 & +4.4 & +4.4 \\
7 & -3.0 & -1.4 \\
8 & +3.2 & +3.4 \\
9 & +1.4 & +1.3 \\
10 & +4.3 & +3.9 \\
\hline
\end{tabular}




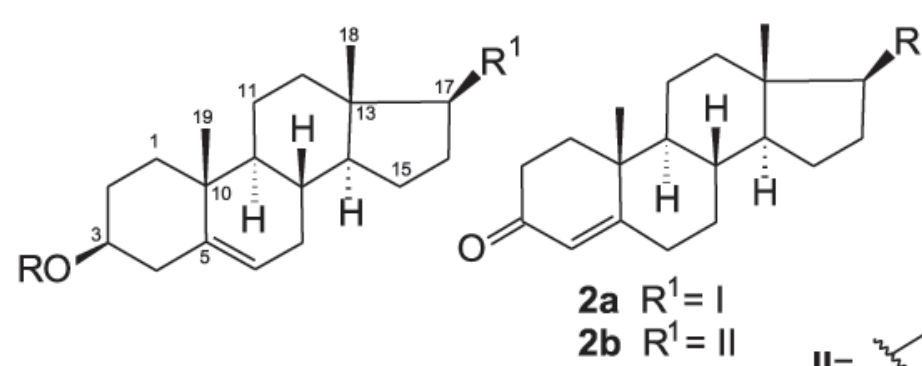

1a $\mathrm{R}=\mathrm{H} ; \mathrm{R}^{1}=\mathrm{I}$

1b $\mathrm{R}=\mathrm{H} ; \mathrm{R}^{1}=$ ॥

3a $R=\beta-D-G l u c o p y r a n o s y l ; R^{1}=$ ।

3b $R=\beta-D-G l u c o p y r a n o s y l ; R^{1}=\|$

$$
\begin{aligned}
& \text { 2a } R^{1}=I \\
& \text { 2b } R^{1}=\|
\end{aligned}
$$<smiles>[R]Oc1c(-c2ccc(OC)c(O)c2)oc2cc(OC)cc(O[R])c2c1=O</smiles>

$4 \mathrm{R}^{1}=\mathrm{H} ; \mathrm{R}^{2}=$ Rutinosyl

$5 \mathrm{R}^{1}=\beta$-D-Glucopyranosyl; $\mathrm{R}^{2}=$ Rutinosyl

$6 \mathrm{R}^{1}=\mathrm{R}^{2}=\mathrm{H}$

\section{Experimental}

\section{General procedure}

The low resolution mass spectra were obtained in a INCOS 50 Finnigan-Mat instrument operating at $70 \mathrm{eV}$ coupled to a GLC 3400 Varian, capillary column (DB-5, $30 \mathrm{~m} \times 0.25 \mathrm{~mm}$ ), det. $280^{\circ}$. Temperature programming from $120^{\circ} \mathrm{C}$ to $180^{\circ} \mathrm{C}$, at $10^{\circ} / \mathrm{min}$, then $40^{\circ} / \mathrm{min}$ to $300^{\circ} \mathrm{C}$. The ${ }^{1} \mathrm{H}$ and ${ }^{13} \mathrm{C}$ NMR spectra, using $\mathrm{CDCl}_{3}$, DMSO- $\mathrm{d}_{6}$ as solvent and TMS as internal reference, were run in a Bruker AC 200. For the column separations Merck silica gel, 63$200 \mu \mathrm{m}$ was used.

\section{Plant material}

The branches of P. macrocarpa (Warm.) R.E. Fries were collected at Instituto of Botânica de São Paulo in June, 1991. A voucher specimen is deposited in the herbarium of the Instituto de Botânica, São Paulo, Brazil under reference SP76791.
Extraction and isolation of the compounds

Dried and powdered branches ( $800 \mathrm{~g}$ ) of P. macrocarpa were extracted with EtOH. The EtOH extract, after concentration in vacuum, was partitioned between $\mathrm{Et}_{2} \mathrm{O} / \mathrm{H}_{2} \mathrm{O}(1: 2)$ giving a water-soluble fraction ( $31 \mathrm{~g})$, an ether soluble (20 $\mathrm{g})$ and an insoluble interface $(2.0 \mathrm{~g})$. The ether soluble part was then partitioned between $\mathrm{MeOH}-\mathrm{H}_{2} \mathrm{O}(9: 1)$ and hexane.

The hexane phase $(10 \mathrm{~g})$ was chromatographed on silica gel column eluted with hexane with increasing amounts of EtOAc. Two fractions were eluted with hexane-EtOAc (9:1). These fractions were, separately, submitted to further purification on silica gel column, eluted with hexane-EtOAc (95:5). The less polar fraction afforded a mixture of steroids $(8 \mathrm{mg}, \mathbf{2} \mathbf{a}+\mathbf{2 b})$ and the more polar fraction afforded another

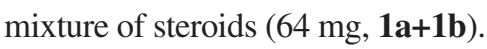

The $\mathrm{MeOH}-\mathrm{H}_{2} \mathrm{O}$ layer $(10 \mathrm{~g}$ ) was chromatographed on silica gel column eluted with $\mathrm{CHCl}_{3}$ with increasing amounts of $\mathrm{MeOH}$. A mixture of steroid glycosydes (27 $\mathrm{mg}, \mathbf{3 a}+\mathbf{3 b}$ ) precipitated from the $\mathrm{CHCl}_{3}-\mathrm{MeOH}(9: 1)$ eluate. The insoluble interface $(2.0 \mathrm{~g})$ was chroma- 
tographed on silica gel column eluted with $\mathrm{CHCl}_{3}$ and increasing amounts of $\mathrm{MeOH}$. The fractions $\mathrm{CHCl}_{3}-\mathrm{MeOH}$ (7:3) and (1:1) treated with $\mathrm{MeOH}$, gave insoluble materials which were, respectively, the flavonoid glicosydes 4 (12 mg) and 5 (168 mg).

Hydrogenation of $\mathbf{M 1}(\mathbf{2} \mathbf{a}+\mathbf{2 b})$. The mixture of $\mathbf{2 a + 2 b}$ (3 mg) dissolved in $\mathrm{CHCl}_{3}$ was maintained under hydrogen atmosphere, for one hour, using $\mathrm{Pd} / \mathrm{C}$ as catalyst to give, after filtration and evaporation of the solvent, $2 \mathrm{mg}$ of sitostenone.

\section{Stigmast-4-en-3-ona (sitostenone)}

EIMS m/z $412\left[\mathrm{M}^{+}(15), 370\right.$ (10), 327(5), 289(15), 229(50), 124(100). ${ }^{1} \mathrm{H} \mathrm{NMR}\left(\mathrm{CDCl}_{3}, 500 \mathrm{MHz}, \delta\right): 5.75$ (s, 1H), 2.35-2.45 (m, 2H), 1.15 (s, 3H), 0.93 (d, 3H), 0.83$0.88(2 \mathrm{~d}, 6 \mathrm{H}), 0.73(\mathrm{~s}, 3 \mathrm{H})$.

\section{Acid hydrolysis}

Flavonoid 5 (50 mg) were hidrolyzed with $20 \mathrm{~mL}$ of 2 mol $\mathrm{L}^{-1} \mathrm{HCl}$ at $80{ }^{\circ} \mathrm{C}$ for $1 \mathrm{~h}$. The precipitate was filtrated, washed with water and after drying afforded $19 \mathrm{mg}$ of $\mathbf{6}$.

\section{(3ß)-Stigmasta-4,22,25-trien--3ol (1b)}

${ }^{1} \mathrm{H}$ NMR: See Table 1; ${ }^{13} \mathrm{C}$ NMR: See Table 2; EIMS $\mathrm{m} / \mathrm{z} 410[\mathrm{M}]^{+}(5), 381$ (5), 300 (17), 273 (9), 272 (23), 271 (52). 255 (27), 213 (18), 187 (12), 185 (15), 173 (18), 171 (13), 163 (19), 161 (23), 159 (41), 147 (34), 145 (48), 143 (21), 138 (43), 137 (42), 133 (47), 131 (29), 129 (17), 123 (16), 121 (32), 191 (38), 109 (95), 105 (58), 95 (100), 84 (3), 79 (65), 69 (31), 67 (64), 57(21), 55(87).

\section{Stigmasta-4,25-dien-3-ona (2a)}

IR $(\mathrm{KBr}) v_{\max } / \mathrm{cm}^{-1}: 1677 ;{ }^{1} \mathrm{H}$ NMR: See Table $1 ;{ }^{13} \mathrm{C}$ NMR: See Table 2; Stigmasta-4,25-dien-3-ona. 410 (18), 381 (1), 327 (37), 312 (8), 297 (20), 281 (20), 271 (10), 270 (15), 269 (30), 245 (19), 229 (14), 207 (54), 149 (17), 148 (12) 147 (26), 138 (5), 135 (18), 134 (11), 133 (25), 124 (26), 123 (20), 121 (21), 119 (20), 109 (22), 107 (25), 105 (26), 95 (32), 93 (27), 91 (32), 84 (52), 83 (20), 81 (33), 79 (32), 69 (40), 67 (32), 55 (100).

(22E)-Stigmasta-4,22,25-trien-3-ona (2b)

IR $(\mathrm{KBr}) v_{\max } / \mathrm{cm}^{-1}: 1677 ;{ }^{1} \mathrm{H}$ NMR: See Table $1 ;{ }^{13} \mathrm{C}$

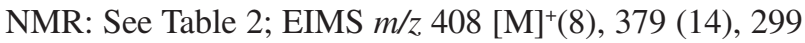
(28), 298 (26), 283 (17), 281 (24), 271 (36), 270 (36), 269 (100), 253 (27), 229 (15), 207 (54), 177 (19), 175 (21), 161 (25), 159 (19), 149 (32), 147 (44), 145 (25), 138 (25), 137
(37), 135 (29), 133 (24), 131 (22), 124 (22), 123 (26), 121

(36), 119 (29), 110 (24), 109 (86), 107 (44), 105 (43), 95

(86), 93 (63), 91 (63), 84 (6), 81 (92), 79 (66), 77 (35), 69 (32), 67 (68), 55 (99)53 (23).

\section{Acknowledgments}

This work was supported by CAPES, CNPq and FAPESP. The authors are grateful to CAPES-PICDT (M.H.C.) and CNPq (N.F.R.) for awards of scholarships. They are also grateful to Dr. Claudia M. Young, Instituto de Botânica, SEMA, São Paulo for the plant material.

\section{References}

1. Murray, N.A.; Sistematic Botany Monographs 1993, 40, 89.

2. Chaves, M. H.; PhD Thesis, Universidade de São Paulo, Brazil, 1996

3. Chaves, M. H.; Roque, N. F.; Phytochemistry 1997, 44, 523.

4. Chaves, M. H.; Roque, N. F.; Phytochemistry 1997, 46, 879.

5. Brochini, C. B.; Núñez, C. V.; Moreira, I. C.; Roque, N. F.; Chaves, M. H.; Quim. Nova 1999, 22, 37.

6. Chaves, M. H.; Santos, L.A.; Lago, J. H. G.; Roque, N. F.; J. Nat. Prod. 2001, 64, 240.

7. González, A.G.; Bermejo, J.; Mediavilla, M.J.; Toledo, F.J.; Rev. Latinoamer. Quim. 1984, 15, 107.

8. Ahmad, V.U.; Aliya, R.; Perveen, S.; Shameel, M.; Phytochemistry 1992, 31, 1429.

9. Tandon, S.; Rastogi, R.P.; Planta Med. 1976, 29, 190.

10. Oger, J.-M.; Richomme, P.; Bruneton, J.; Guinaudeau, H.; J. Nat. Prod. 1991, 54, 273.

11. Goswami, P.; Kotoky, J.; Chen, Z.-N.; Lu, Y.; Phytochemistry 1996, 41, 279.

12. Rauwald, H.-W.; Sauter, M.; Schilcher, H.; Phytochemistry 1985, 24, 2746.

13. Agrawal, P.K.; Carbon-13 NMR of Flavonoids, Elsevier Science: Amsterdan, 1989.

14. Agrawal, P.K.; Rastogi, P.R.; Heterocycles 1981, 16, 2181.

15. Markham K.R.; Ternai,; B. Tetrahedron 1976, 32, 2607.

16. Markham K.R.; Ternai, B.; Stanley R.; Geiger, H.; Mabry, T.J.; Tetrahedron 1978, 34, 1389.

17. Harbone, J.B.; Mabry, T.J.; The Flavonoids: Advances in Reserarch, Chapman and Hall LTD: Londres, 1982.

18. Nasr, C.; Haag-Berrurier, M.; Lobstein-Guth, A.; Anton, R.; Phytochemistry 1986, 25, 770.

19. Inigo,R. P. A.; Iglesias, D. I. A. N.; Phytochemistry 1988, 27, 1230.

Received: August 19, 2002 Published on the web: May 17, 2004

FAPESP helped in meeting the publication costs of this article. 